\title{
A portable, modular, self-contained recirculating chamber to measure benthic processes under controlled water velocity
}

\author{
Janine Rüegg ${ }^{1,2}$, John D. Brant ${ }^{1,3}$, Danelle M. Larson ${ }^{1,4}$, Matt T. Trentman ${ }^{1,5}$, and Walter K. Dodds ${ }^{1,6}$ \\ ${ }^{1}$ Division of Biology, Kansas State University, Manhattan, Kansas 66506 USA
}

\begin{abstract}
We report the design, construction, and functional characteristics of a sealable, portable chamber for measuring benthic metabolic process rates, particularly those under unidirectional flow as found in streams. The design optimizes inherent tradeoffs, such as size, stability, and cost, associated with chambers built for field-based measurements. The chamber is small enough to be portable and minimizes the water-volume:benthic surfacearea ratio. In addition, the chamber is clear to allow measurement of photosynthetic rates. The design minimizes power draw to sustain water velocities found at stream field sites and is modular to allow easy disassembly and cleaning. The design is relatively simple, thereby increasing sturdiness, minimizing construction costs, and decreasing the expertise required to build the unit. We demonstrated the performance characteristics, specifically amperage needed to achieve desired water velocity, flow heterogeneity and turbulence in the working area, the degree of isolation from atmosphere, mixing rate of solute injectate, and heating rate of the chamber. We provide proof of concept with data for in situ benthic rates (gross community production, community respiration, and $\mathrm{NH}_{4}{ }^{+}$uptake). Publications on metabolic chambers built for in situ use do not typically report performance characteristics, so it is difficult to compare our design to existing literature. We include chamber characteristics to clarify the advantages and limitations of benthic rates measured in such chambers.
\end{abstract}

Key words: patch-scale measurements, benthic metabolism, nutrient uptake, air-tight seal

Streams and rivers have global biogeochemical importance (Beaulieu et al. 2011), influence water quality, and transport materials downstream (Mulholland et al. 2008). Most metabolic activity, even in the largest rivers (Dodds et al. 2013), is associated with benthic sediments and nutrient retention (Alexander et al. 2000). The ecological process rates in benthic substrata depend primarily on water velocity, temperature, and light (DeNicola 1996, Berninger and Huettel 1997, Dodds et al. 1999). Thus, equipment to assess benthic activities must enable control of these variables. Chambers that can be sealed against the outside atmosphere are necessary for some measurements that require estimation of flux of a dissolved gaseous phase (e.g., denitrification, respiration, photosynthesis, methanogenesis).

The sealed-chamber approach, in which benthic substrata are removed and placed in a closed-system chamber capable of reproducing the flow characteristics of the stream, has been used to make metabolic measurements at small spatial scales (e.g., Bott et al. 1997). Several approaches can be taken to construct such chambers, but they carry tradeoffs in design and desired study objectives (Dodds and Brock 1998). Tradeoffs include ease of use and the cost and complexity of construction. Simpler designs may be easier to use and cheaper to build but may be unable to recreate flow conditions encountered in the field. Chambers that enable researchers to control temperature and to duplicate in situ light conditions are preferred, but those 2 tasks often interact because sunlight heats the chambers. Fundamental properties of recirculating design and circulation have been discussed by Vogel (1996), who considered attaining laminar flow and moving water with minimal energy costs and economic construction strategies. Dodds and Brock (1998) moved that approach to the field by designing a portable, submersible, sealable, transparent chamber with minimal power consumption. We started our design process based on the principles presented in these

E-mail addresses: ${ }^{2}$ jrueegg@gmail.com; ${ }^{3}$ jbrant@ksu.edu; ${ }^{4}$ Present address: Department of Biological Sciences, Idaho State University, Pocatello, Idaho 83201 USA, larsdane@isu.edu; ${ }^{5}$ Present address: Department of Biological Sciences, University of Notre Dame, Notre Dame, Indiana, 46556 USA, mtrentma@nd.edu; ${ }^{6}$ wkdodds@ksu.edu

DOI: 10.1086/682328. Received 6 June 2014; Accepted 27 October 2014; Published online 8 July 2015.

Freshwater Science. 2015. 34(3):831-844. ๑ 2015 by The Society for Freshwater Science. 


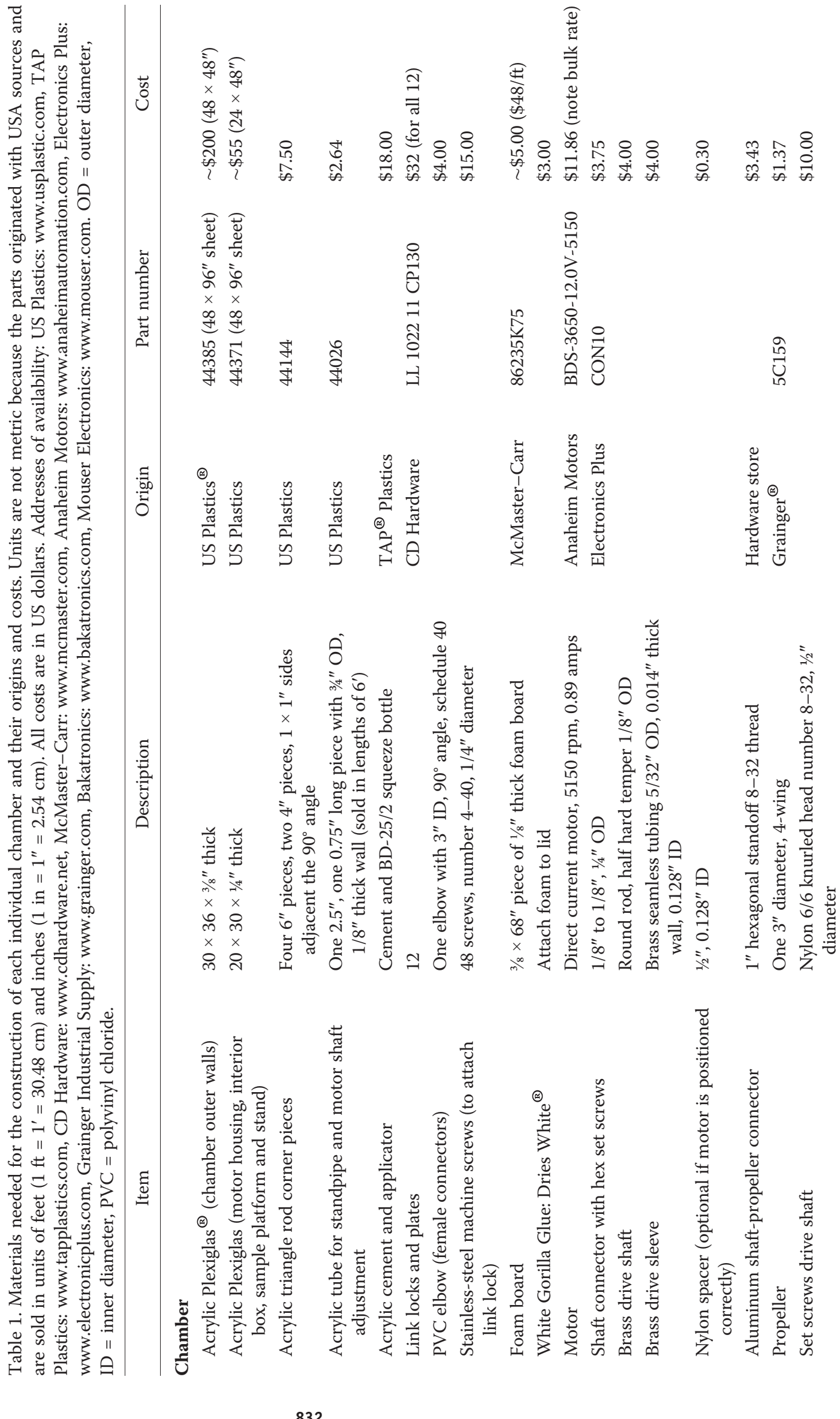




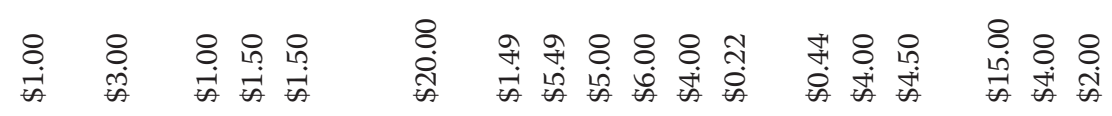
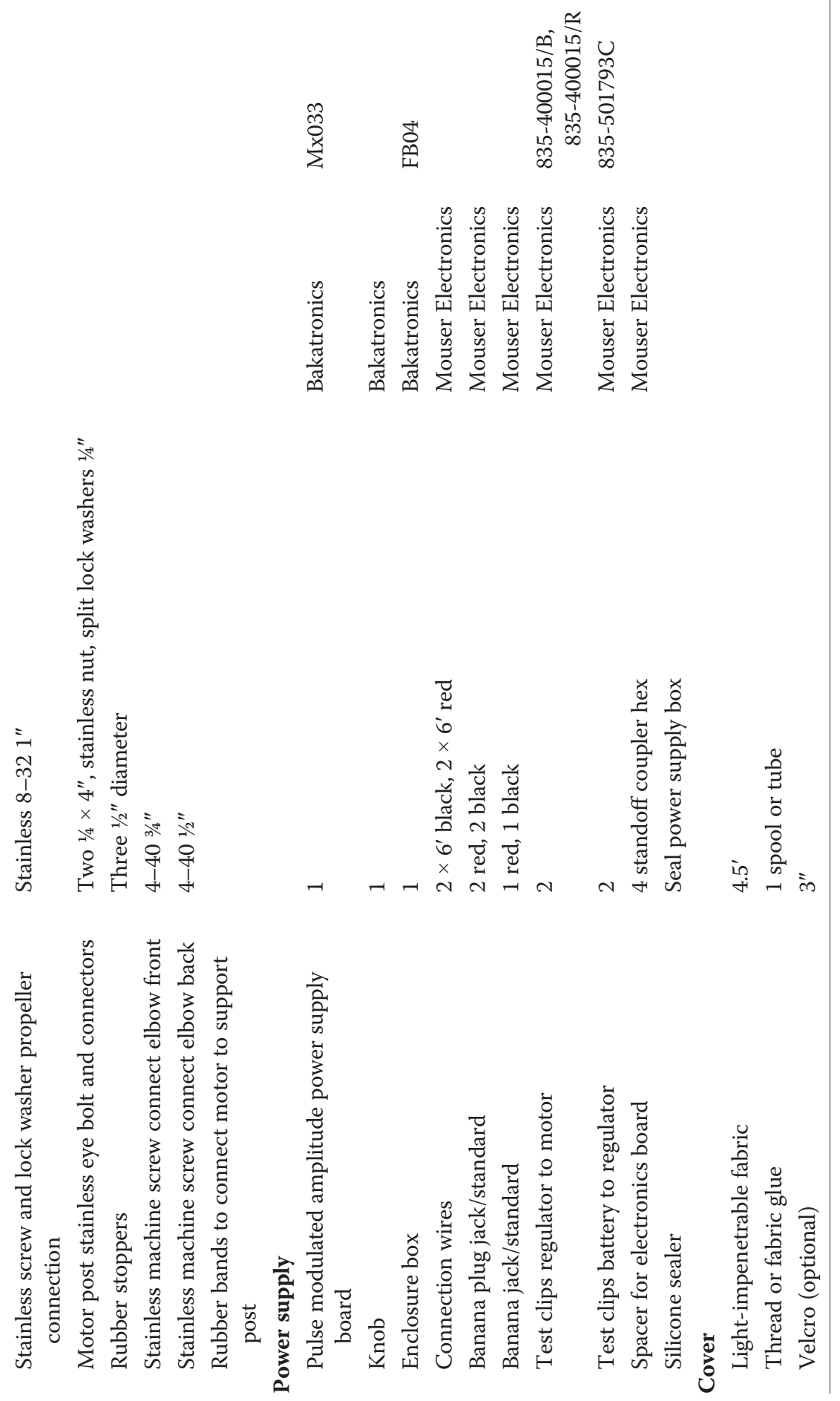
publications, but we addressed issues, such as portability, durability, maintenance, and chamber-volume:sample-area ratio, that arose from past designs.

Here we describe a new recirculating metabolic chamber designed to optimize several criteria. First, we wanted to be able to recreate realistic water velocities and maintain stable water temperature. Second, the chambers had to be sealed to allow measurements of changes in dissolved gas concentrations. Third, we wanted to maximize portability and sturdiness and to minimize power consumption so the chambers could be used in the field rather than being limited to laboratory applications. Fourth, the design of the chambers had to be simple so they would be easy to clean and repair (replaceable individual parts). Fifth, the chambers had to be partially submersible to allow temperature control if needed. Last, we wanted to use affordable and easily obtained materials for construction. Below we detail the necessary parts, construction details, and performance characteristics of our chamber design based on the above criteria.

\section{METHODS}

The following basic features were required to meet our criteria: 1) chamber body built as one unit with reinforced seams for best durability, 2) a relatively large internal propeller driven by an external motor to move water with minimal power required and to avoid heating chamber water, 3) a way to connect an external motor to an internal propeller while maintaining a seal, 4) chamber openings (except for the drain port) at the top of the chamber to minimize pressure-induced leakage and to allow partial to complete submersion of the chamber if needed for temperature control, 5) power supply with minimal power consumption, 6) modest size to allow transportation to remote sites, and 7) minimal chamber-volume:sample-area ratio to minimize the time needed to make each measurement (i.e., to minimize enclosure effects and obtain faster detection of changes).

The chambers include many pieces that can be obtained from online sources (Table 1), as can the specific procedures for assembly of the chamber. We describe key parts and construction below, and we provide supplementary materials (Table S1, Appendices S1, S2) and videos for construction and use (Videos S1-S6), and dimensions (for use with a router) of all pieces (AutoCAD Drawing files [.DWG] that can be exported as machine-readable files; Appendices S1a, b). All measurements are given in inches (in) and feet (ft) with metric equivalents because the materials and parts were sold using those units.

\section{Materials}

We built chambers of clear (92\% transmittance of photosynthetically active radiation [PAR]) acrylic plastic (US Plastics $^{\circledR}$, Lima, Ohio). We used 0.375-in-thick $(0.95 \mathrm{~cm})$ plastic pieces for the outside walls and chamber lid, but constructed inside pieces from 0.25 -in $(0.64 \mathrm{~cm})$ plastic to reduce cost and weight of the chamber. We cut large sheets of acrylic plastic to size with a computerized router at the Kansas State University campus (Appendices S1a, b). Pieces can be cut with mechanical saws, but this process may result in edges that are rougher and require more work to smooth to create a tight seal. We recommend cutting by hand only for low-tolerance or replacement parts. All pieces require smoothing with a carbide scraper, file, and wetable (i.e., wet/dry) sandpaper to ensure smooth surfaces for tight seals. We programmed the router to drill the holes necessary for screws, the probe portal, shaft connection, and drain hole. We tapped screw holes by hand before the pieces were connected. A few holes were on the edges of cuts (e.g., holes for link-lock hooks on the lid) and could not be drilled by the router, so we drilled them by hand on a drill press.

\section{Construction}

We provide detailed instructions for construction of a chamber in the supplemental materials (Videos S1-S6) and highly recommend that users view these videos before constructing and using chambers. However, we emphasize the most important steps here. The chamber has 4 main parts: 1) the outside box (Fig. 1A, B, C), 2) the dead-space box (Fig. 1D, E), the motor/propeller housing (Fig. 1H, I), and 4) the lid (see Appendix S2 for a CAD model [opensource software FreeCAD]).

First, we constructed the outside box with an inside table (Fig. 1A-C). We connected the side edges to the bottom, making sure the pieces were properly oriented (Fig. 1A, B, Table 2, Video S1). We began with an end piece (B1), followed by a side piece (C1), the other end piece (B2), and the other side (C2). End pieces (B1, B2) are interchangeable, but the holes for the link-locks must be on top and outside the chamber. On each side piece $(\mathrm{C} 1, \mathrm{C} 2)$, the holes for link-lock attachment should be on top and outside the chamber, and the end of each piece with holes at a larger distance from the end should be at the chamber end with the drain hole (Fig. 1A, B, Fig. 2A). We positioned each piece, held it in place with clamps (corner clamps and standard bar clamps to achieve compression), and applied acrylic cement to the seam to seal the pieces together. A good working seal required $\sim 15 \mathrm{~min}$ and a full-strength seal $\sim 12 \mathrm{~h}$ of compression. Our next step was to install the triangular corner reinforcement pieces (D) (Fig. 1B, Video S2). The next pieces affixed to the outer box were the stilts (E) on which a removable sample platform (table; G) rests to support the sample and to separate the return flow from the flow across the sample. The stilts also strengthen the bottom chamber seams. We cut the stilt pieces (E) at a $45^{\circ}$ angle on one end to conform to the triangular reinforcement pieces on the side with the drain 
A

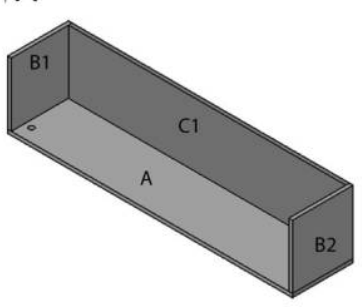

D

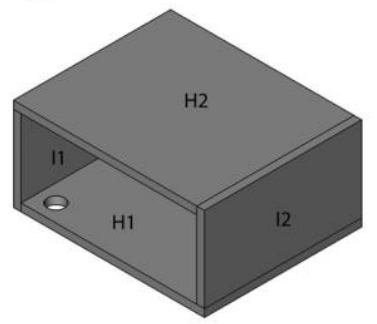

G

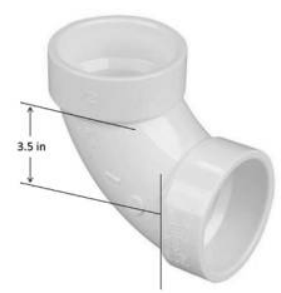

B

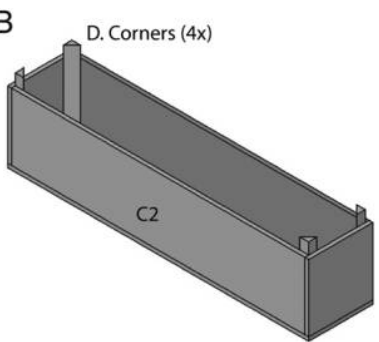

E
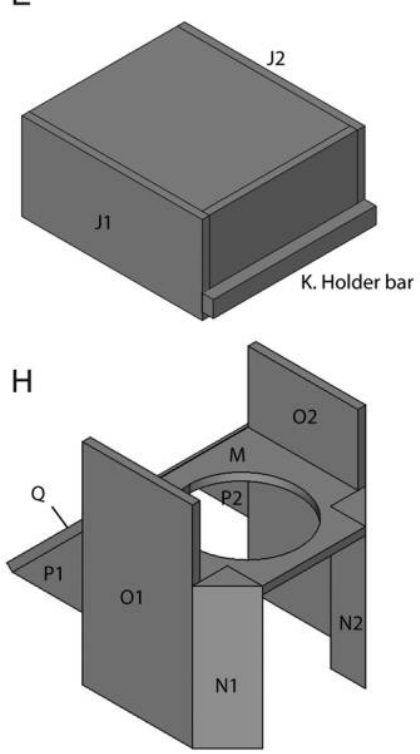

$\mathrm{C}$
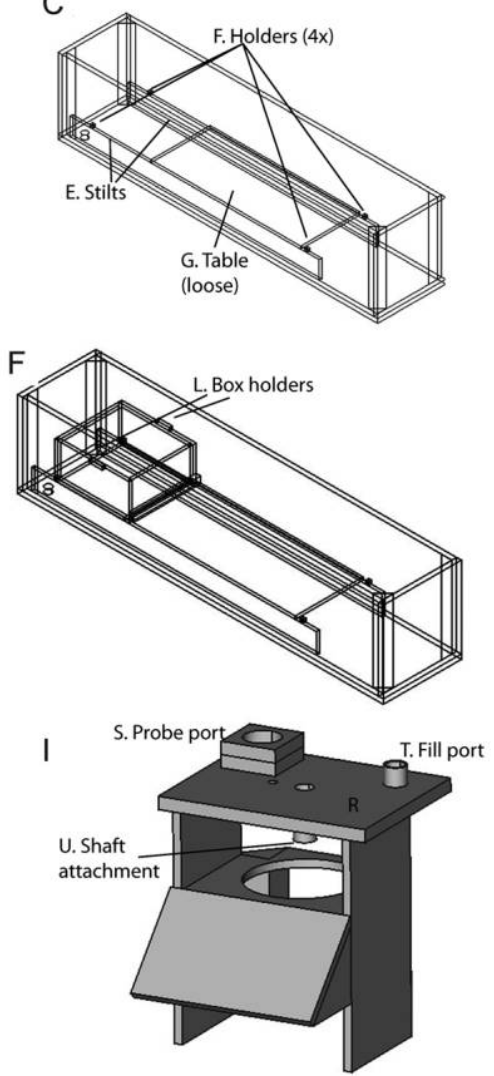

Figure 1. Schematics showing the steps necessary to construct a chamber. A.-Starting the outer box. B.-Finishing outer chamber and adding corner pieces. C.-Final parts of the outer chamber. D and E.-Dead space (spacer) box. F.-Fitting spacer box into the main body of the chamber. G.-Schematic for cutting the polyvinyl chloride (PVC) elbow. H and I.-Propeller/motor housing (PVC not shown). See Table 2 for detailed description of acrylic pieces. Appendices S1a, b, and S2 provide router-readable files for cutting acrylic pieces and a CAD model of the chamber, respectively.

hole. We compressed the stilt pieces with a cable turnbuckle to achieve outward pressure while the cement was curing. We cemented small pieces (longitudinal holders; F) to hold the dead-space box in position (Fig. 1C). Last, we attached the 10 link-locks to seal the lid and the motor housing.

We constructed 2 elements inside the chamber to create and direct flow: the dead-space box (spacer box) (Fig. 1D, E) and the motor/propeller housing (Fig. 1H, I). Water circulates in a vertical loop. It flows below the table $(G)$ and the spacer box, rises and flows between the spacer box and the end of the chamber, then flows over the spacer box under the lid, through the sampling area, and down at the opposite end where the propeller pushes the water under the sampling platform (Fig. 2A). We constructed the fully enclosed spacer box by cementing pieces in a specific order. First, we attached a front/back (I1, I2) to a top/bottom piece $(\mathrm{H} 1, \mathrm{H} 2)$ to make $2 \mathrm{~L}$-shaped sets, which were then connected (Fig. 1D). Second, we cemented the side pieces $(\mathrm{J} 1, \mathrm{~J} 2)$ to close the box and attached the holder bar (K; Fig. 1E), which prevents the sample table (G) from float- ing. Last, we attached 2 vertical holder pieces (L; Fig. 1F) to the outside of the outer box to prevent it from moving upward.

Next, we built the propeller housing (motor housing), which holds the propeller and motor in place and creates flow in the chamber (Videos S3, S4). We removed the connection ends of a polyvinyl chloride (PVC) elbow (3-in diameter, female, $90^{\circ}$ angle) with a radial arm saw and cut part of the end perpendicular to the vertical opening so the bottom of the elbow would be flush with the bottom of chamber to a height of $3.5 \mathrm{in}(8.9 \mathrm{~cm}$; Fig. 1G). We affixed the elbow to a plastic holder plate (M) with screws (see Appendices S1b, S2 for exact placement of holes). We kept the holder plate level with 2 triangular supports (N1, $\mathrm{N} 2$ ) fit into the cutout covers of the holder plate (M) and 2 stilts $(\mathrm{O} 1, \mathrm{O} 2)$ along the outside edge. The front of the propeller housing has an acrylic piece attached at a $45^{\circ}$ angle with 2 triangular holders (P1, P2) (Fig. 1H) to direct and separate the flow paths and to hold the table in place (ramp [Q]). The top of the propeller housing (R) holds the sampling $(\mathrm{S})$ and fill (T) ports, and the propeller motor and 


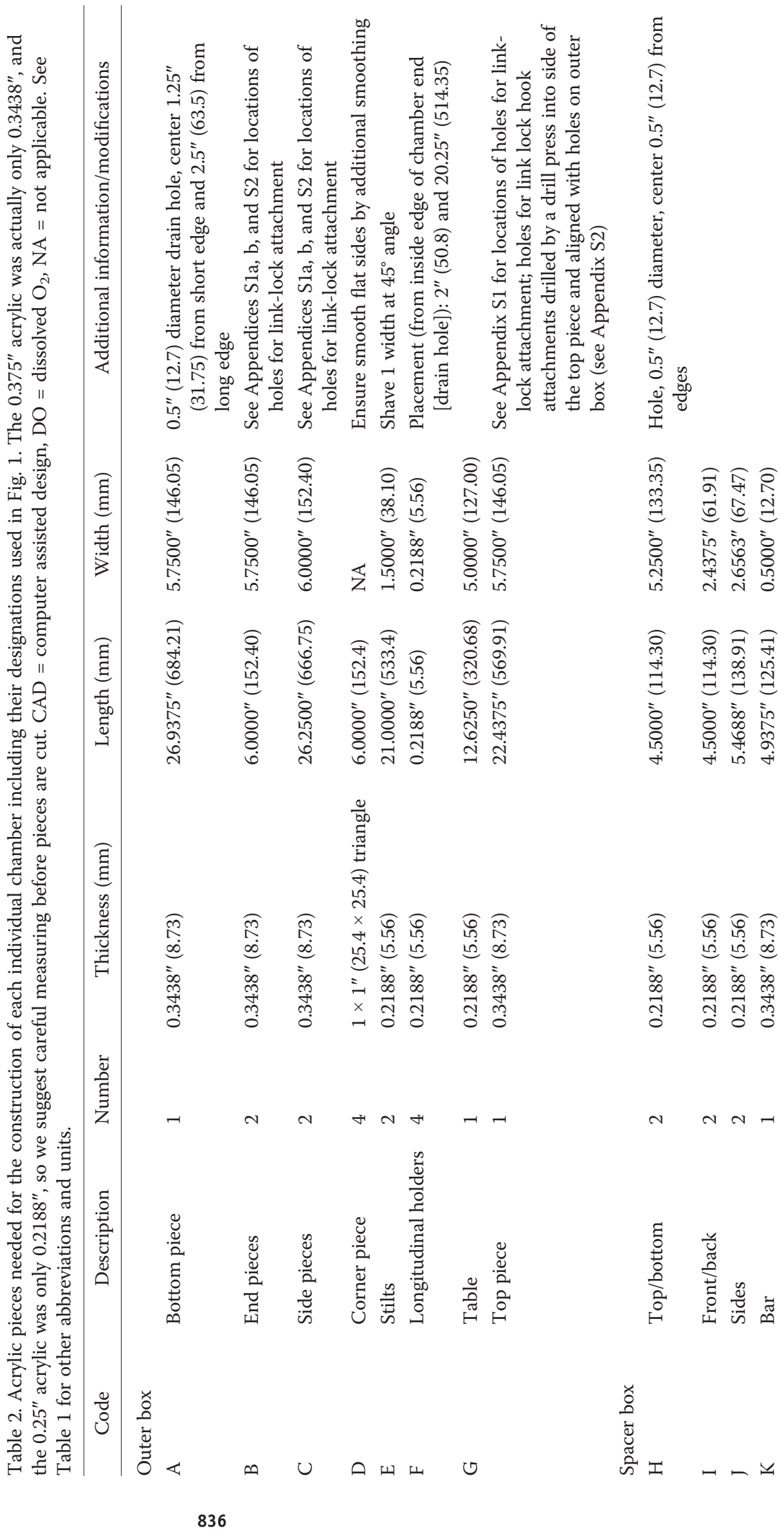

This content downloaded from 129.130.037.190 on February 24, 2016 13:06:49 PM 

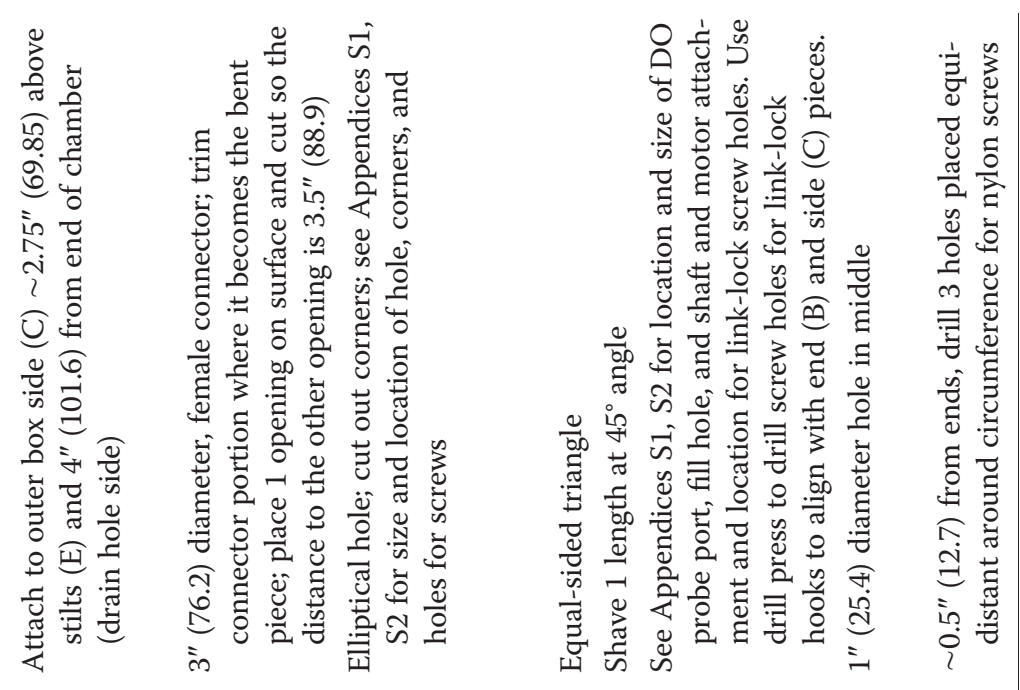

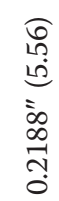
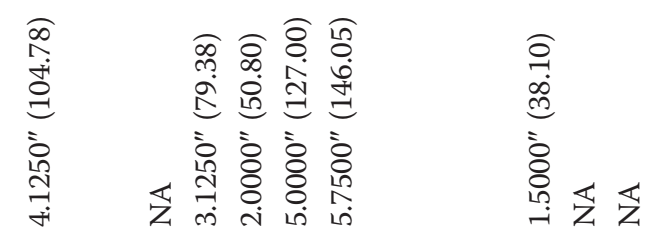

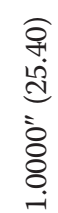

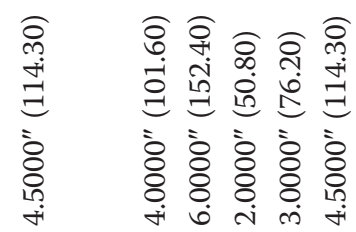

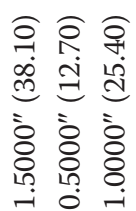

일

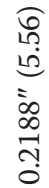

ล)

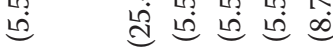

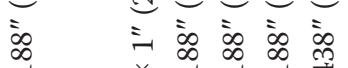

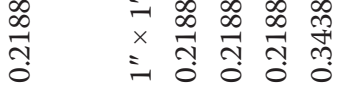

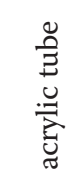

กิ

$\infty \stackrel{0}{\infty}$

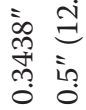

N

$-$

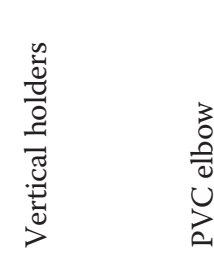
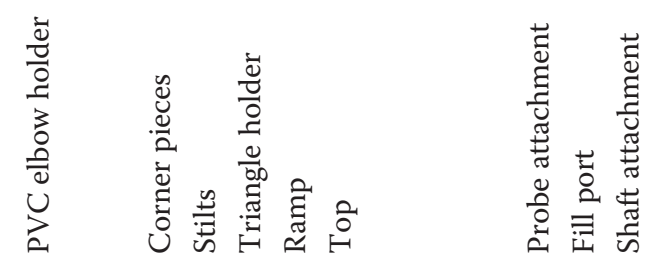

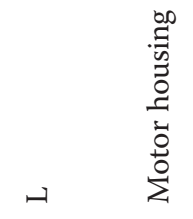
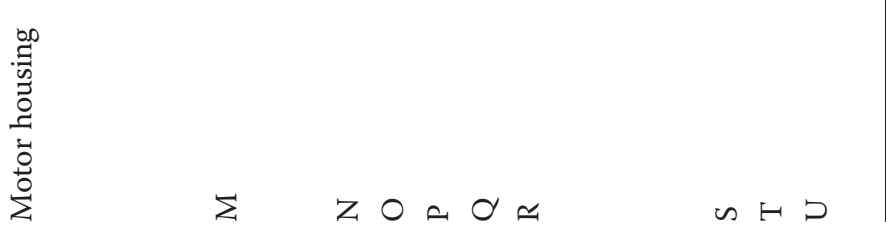

837

This content downloaded from 129.130.037.190 on February 24, 2016 13:06:49 PM 


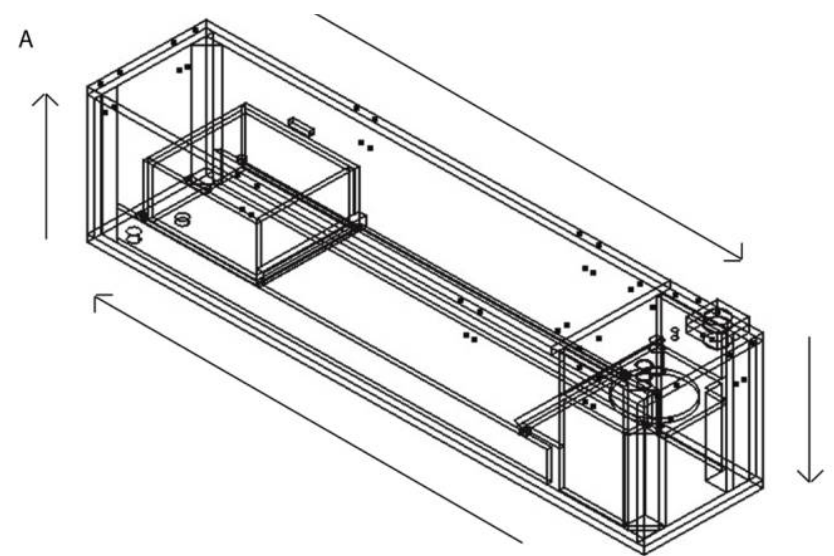

B

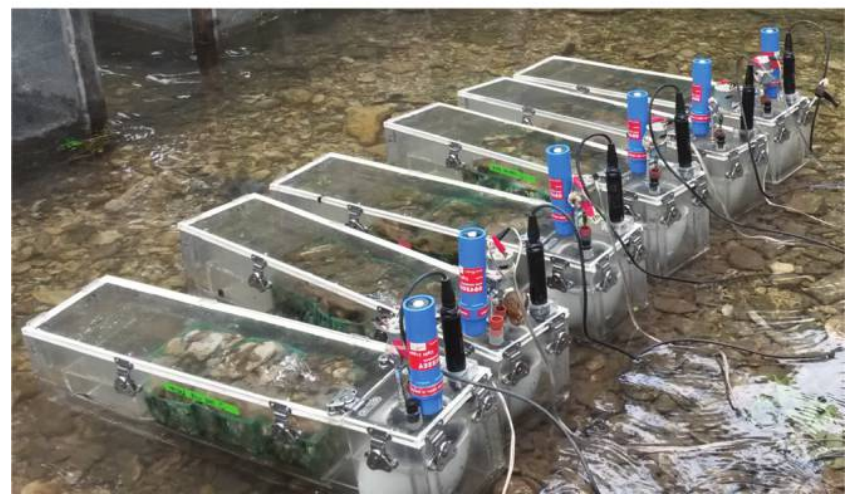

Figure 2. A.-Schematic of entire chamber (polyvinyl chloride not shown) with arrows indicating direction of flow. B.-Six chambers in use.

is fashioned to allow the chamber and the lid to be sealed together (Fig. 2A).

The propeller was connected to the motor with a drive shaft (Video S5, Fig. S1). The brass drive shaft was held in place by a brass sleeve with a slightly larger inner diameter than the outer diameter of the shaft (Table 1). Outside the chamber, we attached the brass sleeve to the motor by a coupler with 2 set-screws. We used a small $(12 \mathrm{~V}$, $5150 \mathrm{rpm}, 0.89 \mathrm{~A}$ DC) motor to power the propeller, but larger motors with more power draw could be used. The top of the shaft passes through the outside of the chamber and is held in place with a rubber stopper. An acrylic tube attached to the top of the housing and protruding into the chamber toward the center of the PVC input has 3 nylon screws that hold the brass sleeve and are used to make fine adjustments for propeller placement. A small piece of plastic tubing around the brass sleeve creates a point of contact to allow better positioning by the nylon screws. The propeller is attached with a set-screw at the bottom of the shaft. This design does not offer an absolute seal, but because the tolerances of shaft, brass sleeve, and stopper are tight and are connected to the top of the chamber, the interface with the atmosphere is minimal (see Results). A tighter seal can be obtained with more expensive machined shafts, such as those that drive modelboat propellers.

Last, we attached 0.375 -in-wide $(0.95 \mathrm{~cm})$ strips of foam sheeting (Table 1) to the edges of the chamber lid (top and motor housing) with silicone sealer. The complete chamber included the sample table, held in place by the $45^{\circ}$ piece of the propeller housing box and the bar of the spacer box. An open area between the end of the chamber and the end of the spacer box allowed water to flow up and over the sample platform back to the propeller housing box (Fig. 2A, B).

\section{Power supply}

We designed the chambers to run on a $12-\mathrm{V}$ battery in the field or connected to a $12-\mathrm{V}$ DC power transformer in the laboratory. The motor was connected to a power supply box that allowed us to control propeller speed by regulating current by pulsing DC voltage. If power availability is not a factor, resistor-based power supplies can be used and will allow the propeller to be driven more smoothly at lower speeds.

\section{Cover}

We needed to be able to alter light intensity in the chambers when measuring metabolism (e.g., dark conditions for measuring respiration). We made a simple rectangular fabric cover that required minimal sewing or fabric glue to hold the 4 seams (Fig. S2). We recommend opaque fabric, such as denim/twill, gingham, jacquard, piqué, or polyester. We cut a 2.5-in $(\sim 6 \mathrm{~cm})$ slit in the top side of the cover as access for the $\mathrm{O}_{2}$ probe and to allow the motor to be outside the cover. We added Velcro ${ }^{\circledR}$ to the underside of the fabric beside the slit to seal the fabric around the probe and shaft, thereby minimizing light entering the chamber.

\section{Chamber characteristics}

We used a volumetric cylinder to measure the volume of water needed to fill 3 chambers in the laboratory (Video S6). We established relationships between current and water velocity by varying current (Ampere) provided to the motor while monitoring velocity $(\mathrm{m} / \mathrm{s})$. We used a submerged thermistor flow meter (LaBarbera and Vogel 1976, Vogel 1996) to measure velocity in the chambers $2 \mathrm{~cm}$ above the substratum surface (acrylic plastic piece placed flush with the spacer box) in the center of the sample table. We inserted the probe through a chamber lid with a hole drilled in the center of the working area. We tested for effects of substratum size on velocity with 3 sample containers $(10-\times 10-\times 6-\mathrm{cm}$ strawberry baskets $)$ in the sample location. Substrata used were a smooth acrylic plastic piece (placed on top of sample containers), small pebbles $(<0.2 \mathrm{~cm})$, medium pebbles (mean $\pm \mathrm{SD}$; $0.7 \pm$ 
$0.4 \mathrm{~cm})$, and large pebbles $(4.3 \pm 1.47 \mathrm{~cm})$ measured as the median diameter of the individual rocks.

We characterized 3-dimensional flow and turbulence with an Acoustic Doppler Velocity meter (Vectrino; Nortek, Boston, Massachusetts) in the working area with a smooth acrylic plastic piece as the substratum (placed flush with the spacer box). Because of distance and size constraints of the probe, we were able to characterize only a portion of the working area with a partially closed lid (open for the last few $\mathrm{cm}$ before the motor housing). We were able to measure velocity across a grid starting at the edge of the spacer box up to about the middle of the working area. We measured 5 points across the chamber $(2.5,4.5,6.5$, $8.5,10.5 \mathrm{~cm}$ from the one side) at each of 6 transects along the flow axis $(2,4,6,8,10,12 \mathrm{~cm}$ from the edge of the spacer box). We measured 1000 points at each location $(n=30)$ at a frequency of $25 \mathrm{~Hz}$. We calculated the turbulence intensity as the mean standard deviation across all 3 axes $(x, y, z)$ relative to mean velocity in direction of flow ( $x$ axis $)$

$$
\left(\frac{\sqrt{\operatorname{var}_{x}+\operatorname{var}_{y}+\operatorname{var}_{z}}}{3 \operatorname{mean}_{x}}\right) .
$$

We tested for isolation from atmosphere by bubbling $\mathrm{N}_{2}$ gas into the water in the chambers to deplete the dissolved $\mathrm{O}_{2}$ to below saturation $(79 \%)$ at $7.18 \mathrm{mg} / \mathrm{L} \mathrm{O}_{2}$. We then sealed the chambers and logged $\mathrm{O}_{2}$ using a handheld optical $\mathrm{O}_{2}$ meter (ProODO; Yellow Springs Instruments, Yellow Springs, Ohio) for $2 \mathrm{~h}$. The $\mathrm{O}_{2}$ probe was sealed to the top of the propeller housing box with a threaded attachment piece constructed to match the probe.

We tested time to complete mixing of solutes injected into chambers by measuring changes in conductivity (Model 103 digital conductivity meter placed in sampling port immediately above propeller; Markson, Henderson, North Carolina) after injections of $3 \mathrm{~mL}$ saturated $\mathrm{NaCl}$ solution under different flow regimes (slow $=0.2 \mathrm{~A}$, medium $=0.5 \mathrm{~A}$, fast $=1.5 \mathrm{~A} ; \sim 3,6$, and $12 \mathrm{~cm} / \mathrm{s}$, respectively).

\section{In situ chamber use on natural substrata}

We conducted short-term community respiration (CR), net community productivity (NCP), and $\mathrm{NH}_{4}{ }^{+}$uptake measurements of $300 \mathrm{~cm}^{2}$ (surface area) of substratum in Kings Creek on the Konza Prairie Biological Station outside Manhattan, Kansas, USA, in August 2012. We placed streamequilibrated substrata (one set of three $10-\times 10-\times 6-\mathrm{cm}$ plastic baskets/chamber) on the sample table inside 2 chambers. We filled the chambers with stream water and closed them before removing air bubbles and sealing an $\mathrm{O}_{2}$ probe to the top of the propeller housing box. We recorded the total volume of water needed to fill the chamber without bubbles. We placed the chambers on the stream bank close to the stream.
After ensuring an air-tight seal, we turned the motor on and measured $\mathrm{O}_{2}$ and temperature at 1-min intervals while each chamber was wrapped in its cover to estimate $\mathrm{CR}$. We ran the chambers until a $1.0 \mathrm{mg} / \mathrm{L}$ decrease was measured or $2 \mathrm{~h}$ had passed. We measured PAR (Odyssey Irradiance logger; DataFlow Systems, Christchurch, New Zealand) for the duration of the collection period at the same 1-min interval to assess our effectiveness in establishing a dark treatment. Then we removed the cover and estimated NCP by measuring $\mathrm{O}_{2}$, temperature, and PAR for the amount of time used to measure $\mathrm{CR}$.

After measuring metabolic rates, we estimated $\mathrm{NH}_{4}{ }^{+}$ uptake following procedures of O'Brien and Dodds (2008). We added $3 \mathrm{~mL}$ of an ammonium chloride stock solution $\left(5.5 \mathrm{gNH}_{4} \mathrm{Cl} / \mathrm{L}\right)$ to each chamber. The amount was calculated to raise the background concentration of $\mathrm{NH}_{4}^{+}$ roughly $5 \times$. We waited $5 \mathrm{~min}$ after adding the $\mathrm{NH}_{4}{ }^{+}$solution to collect the $1^{\text {st }}$ sample to allow for thorough mixing, and we took 4 more samples, spaced according to exponential mass loss. We filtered the samples, placed on them on ice, and subsequently froze them until we analyzed them in the laboratory with the phenol-hypochlorite method (Solorzano 1969) on a Technicon AutoAnalyzer (SEAL Analytical, Mequon, Wisconsin).

We fit linear regressions to changes in $\mathrm{O}_{2}$ over time in the dark and the light, and to changes in $\mathrm{NH}_{4}{ }^{+}$concentration over time to calculate CR, NCP, and $\mathrm{NH}_{4}{ }^{+}$uptake rates. We used chamber volume and the surface area of substrata $\left(3 \times 100 \mathrm{~cm}^{2}\right)$ to calculate areal hourly rates. We also fit linear regressions to calculate relationships among current, velocity, and substrata. We did regressions in $\mathrm{R}$ (version 2.15.1; R Project for Statistical Computing, Vienna, Austria).

\section{RESULTS}

\section{Volume and velocity}

The total chamber volume without baskets or substrata was $10.8 \pm 0.13 \mathrm{~L}(\mathrm{SD} ; n=3)$. With substrata in the chambers, the volume decreased by as much as $1.5 \mathrm{~L}$ for $6 \times 10 \times 30 \mathrm{~cm}$ samples of gravel. Thus, the actual volume to fill the chambers must be measured with the substrata in place for accurate estimates of metabolic and nutrient uptake rates to be made.

Flow velocity in the chambers ranged from 0 to $0.14 \mathrm{~m} / \mathrm{s}$ (Fig. 3A). Motor current linearly predicted water velocity up to $1 \mathrm{~A}$ (simple linear regression [SLR]: velocity $[\mathrm{m} / \mathrm{s}]=$ $\left.0.106 \mathrm{~A}+0.015 ; r^{2}=0.70\right)$. The chambers varied slightly in their current-velocity relationships, probably because of small differences in power transference caused by shaft alignment, but the relationships for all chambers were linear (SLR: $r^{2}>0.90$; Fig. 3A). If a precise velocity is needed, we suggest calibrating each chamber with flow meters before use. Substratum type did not affect the current-velocity relationships (Fig. 3B). Achieving low velocities $(<0.03 \mathrm{~m} / \mathrm{s})$ 


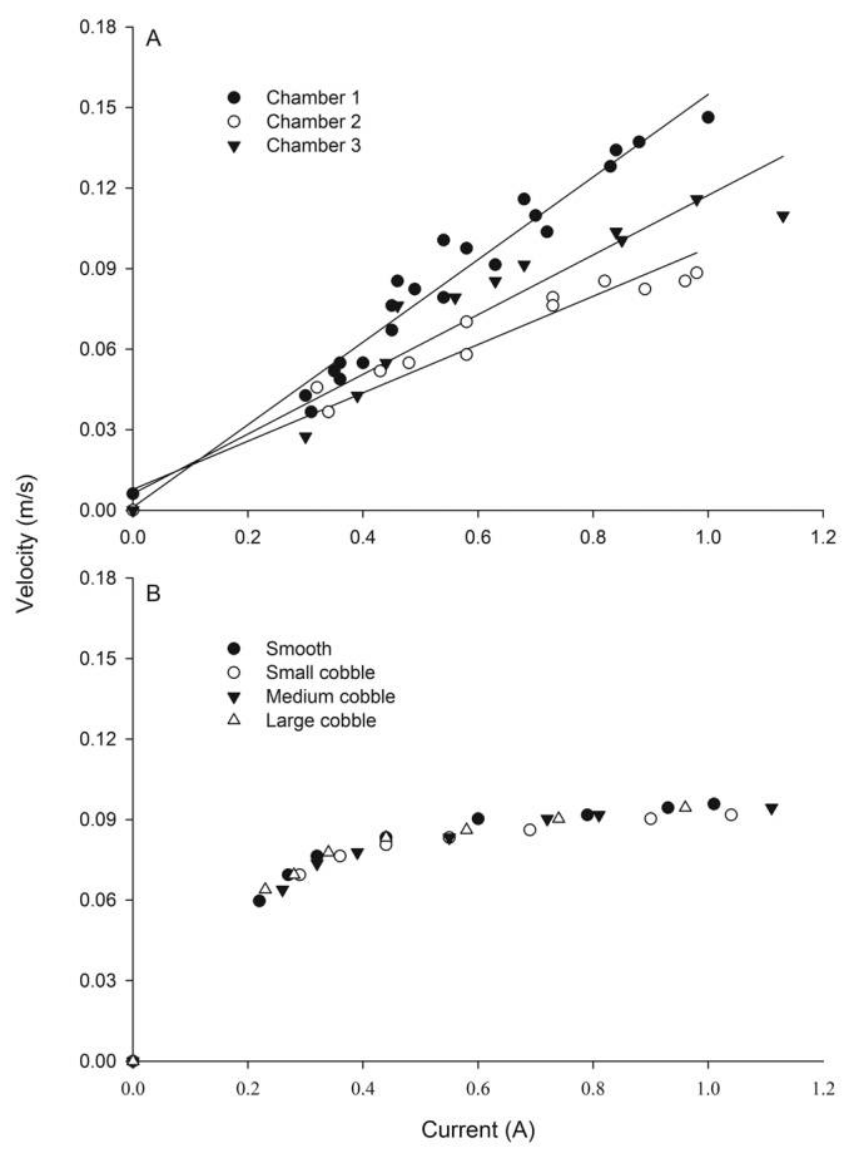

Figure 3. Relationships between current provided to the motor and flow velocity in the chambers separated by individual chambers (to visualize variance) (A) and with different substrata in chamber 2 (B). Substrata used were a smooth plastic top, small pebbles $(<0.2 \mathrm{~cm})$, medium pebbles $(0.7 \pm 0.4 \mathrm{~cm})$, and large pebbles $(4.3 \pm 1.47 \mathrm{~cm})$. All lines represent linear regressions.

was difficult because we used a pulsed power control. These low velocities could be achieved with a different motor or a variable-resistor power control.

Flow velocities were relatively consistent across the working area (Fig. 4A, D, G), velocities perpendicular to flow were a fraction of main flow velocities (Fig. 4B, E, H), and turbulence was lowest at intermediate current (Fig. 4C, F, I). At low current $(0.2 \mathrm{~A})$, flow velocity ranged from 0.02 to $0.12 \mathrm{~m} / \mathrm{s}$ with an average velocity of $0.04 \mathrm{~m} / \mathrm{s}$. The high velocities can be attributed to one localized area (Fig. 4A). At medium current $(0.5 \mathrm{~A})$, flow velocities ranged from 0.07 to $0.13 \mathrm{~m} / \mathrm{s}$ with an average of $0.10 \mathrm{~m} / \mathrm{s}$ (Fig. 4D), whereas high current $(1.5 \mathrm{~A})$ produced velocities that ranged from 0.10 to $0.17 \mathrm{~m} / \mathrm{s}$ with an average of $0.14 \mathrm{~m} / \mathrm{s}$ (Fig. 4G). Thus, velocities varied $<15 \%$ (coefficient of variation) at the higher amperages. Velocities perpendicular to main flow directions were low (Fig. 4B, E, H) and ranged from -0.10 to $0.05 \mathrm{~m} / \mathrm{s}$ across all current settings. Turbulence intensity was lowest at the medium current setting (Fig. 4F) and increased with higher current. However, some of the turbulence at higher current settings may have been because the lid was not closed all the way to allow access for the probe.

\section{Isolation from atmosphere}

The experimentally reduced $\mathrm{O}_{2}$ in a chamber increased linearly over time as the chamber equilibrated with the outside atmosphere (SLR: slope $=0.0006 \mathrm{mg} \mathrm{O}_{2} \mathrm{~L}^{-1} \mathrm{~min}^{-1}$; $\left.r^{2}=0.907\right)$, and gained $\sim 0.03 \mathrm{mg} \mathrm{O}_{2} \mathrm{~L}^{-1} \mathrm{~h}^{-1}$ via atmospheric exchange (Fig. $5 \mathrm{~A}$ ). The $\mathrm{O}_{2}$ probes we used generally drifted substantially less $\left(0.01 \mathrm{mg} \mathrm{O}_{2} \mathrm{~L}^{-1} \mathrm{~d}^{-1}\right)$, but the $0.01 \mathrm{mg} \mathrm{O}_{2} / \mathrm{L}$ precision of the meters placed us just inside the limits of the probe to detect the slight exchange with the atmosphere. Thus, the chambers are not completely sealed from the atmosphere and should be used for the shortest possible incubation times. Given the area of the sample holding compartment $\left(0.03 \mathrm{~m}^{2}\right)$ and assuming a chamber volume of $10 \mathrm{~L}$, the rate of exchange could result in an error of $10 \mathrm{mg} \mathrm{m}^{-2} \mathrm{~h}^{-1}, \sim 1 / 20^{\text {th }}$ the rates measured in our field trials.

\section{Solute mixing patterns}

Solutes were mixed completely $<1$ min after addition (range: $10-50 \mathrm{~s}$ ). The mixing time was slightly dependent on flow velocity, and faster flows lead to faster mixing (Fig. 5B-D). We also varied location of injection for medium velocities, and injections closer to the propeller mixed faster $(20 \mathrm{~s}$ at the medium current setting [0.5 A]).

\section{Field assessment of metabolic and nutrient uptake rates}

We provide representative data from one of our measurement series to illustrate performance characteristics of the chambers in the field. Field incubations shown here were done at extreme conditions $\left(>40^{\circ} \mathrm{C}\right.$ air temperature under full sun), but chambers were on land rather than partially submerged in the stream for this trial. Temperature increased over the course of these measurements at a rate of $\sim 1^{\circ} \mathrm{C} / \mathrm{h}$ regardless of whether chambers were covered (SLR: slopes $=0.026$ and $0.019^{\circ} \mathrm{C} / \mathrm{min}$ for chambers 1 and 2, respectively; $r^{2}>0.970$ ) (Fig. 6A).

The dark cover reduced light levels to below detection. $\mathrm{O}_{2}$ decreased in the dark and increased in the light in both chambers (Fig. 6A, Table 3). To test the shortest appropriate sampling period, we compared slopes for the first 5 to $30 \mathrm{~min}$ in 1-min steps and found that after a 12-min sampling period slopes changed $<5 \% /$ additional minute. We converted slopes to rates for CR (dark treatments), NCP (light treatments), and $\mathrm{NH}_{4}{ }^{+}$uptake (see below) as: 


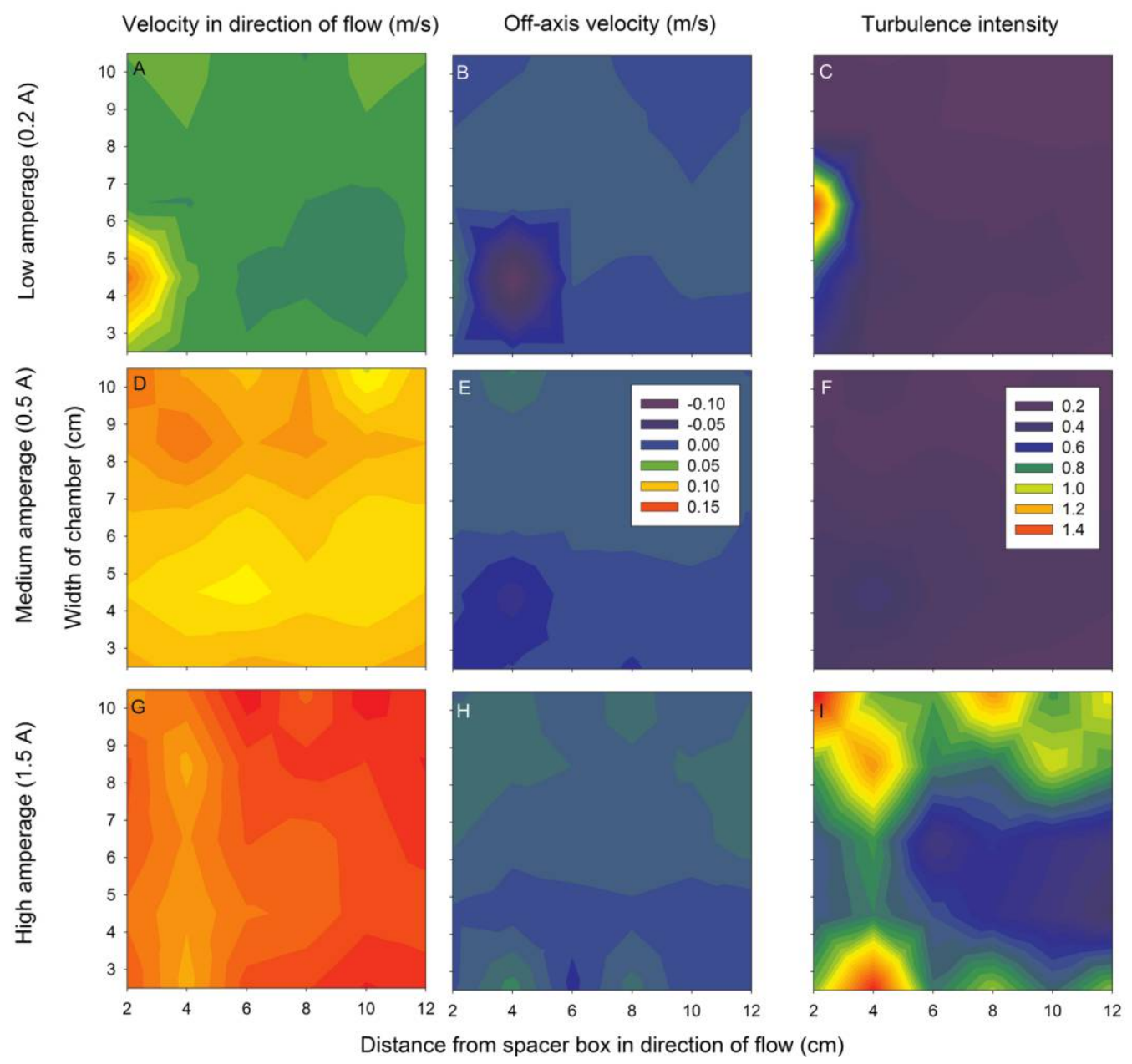

Figure 4. Flow profiles of a portion of a chamber working area with motor currents of $0.2 \mathrm{~A}(\mathrm{~A}-\mathrm{C}), 0.5 \mathrm{~A}(\mathrm{D}-\mathrm{F})$, and $1.5 \mathrm{~A}(\mathrm{G}-\mathrm{I})$ showing velocity profiles in the direction of flow $(x)(\mathrm{A}, \mathrm{D}, \mathrm{G})$, mean velocities of the cross-sectional plane $(y$ and $z)(\mathrm{B}, \mathrm{E}, \mathrm{H})$, and turbulence intensity (mean standard deviation of $x, y$, and $z$ axes relative to mean velocity in direction of flow) $(\mathrm{C}, \mathrm{F}, \mathrm{I})$.

$$
\begin{aligned}
& \operatorname{rate}\left(\left[\mathrm{g} \mathrm{O}_{2}\right] \text { OR }\left[\mathrm{mg} \mathrm{NH}_{4}^{+}-\mathrm{N}\right] \mathrm{m}^{-2} \mathrm{~h}^{-1}\right)= \\
& \frac{\text { slope }\left(\mathrm{mg} \text { OR } \mu \mathrm{g} \mathrm{L}^{-1} \mathrm{~min}^{-1}\right) \times 60(\mathrm{~min} / \mathrm{h}) \times \text { chamber volume }(\mathrm{L})}{\operatorname{area}\left(\mathrm{m}^{2}\right) \times 1000(\mathrm{mg} / \mathrm{g} \text { OR } \mu \mathrm{g} / \mathrm{mg})}
\end{aligned}
$$

where chamber volume was 10.0 and $10.2 \mathrm{~L}$ for chambers 1 and 2, respectively, and surface area of sample baskets was $0.03 \mathrm{~m}^{2}$. CR was 0.220 and $0.306 \mathrm{~g} \mathrm{O}_{2} \mathrm{~m}^{-2} \mathrm{~h}^{-1}$ for chambers 1 and 2, respectively. Gross community production (GCP) as the sum of CR and NCP was 0.560 and $0.469 \mathrm{~g} \mathrm{O}_{2} \mathrm{~m}^{-2} \mathrm{~h}^{-1}$, respectively.

$\mathrm{NH}_{4}{ }^{+}$concentrations decreased linearly during the chamber run. $\mathrm{NH}_{4}{ }^{+}$concentration decreased by $1 / 6$ in $120 \mathrm{~min}$ and $1 / 3$ in $60 \mathrm{~min}$ for chambers 1 and 2, respectively (Fig. 6B, Table 3). Similar to calculations for CR, the slopes indicate a nutrient uptake of 0.016 and $0.046 \mathrm{mg} \mathrm{NH}_{4}{ }^{+}-\mathrm{N} \mathrm{m}^{-2} \mathrm{~h}^{-1}$, respectively.

The chambers were deployed at 5 stream sites (Puerto Rico, North Carolina, Kansas, and 2 Alaskan sites). We shipped sets of 7 chambers from Kansas to Puerto Rico, Georgia, and Alaska by commercial carriers. Chambers were transported in boxes with 2-cm thick foam padding, placed in the bed of a pickup truck, carried by all-terrain vehicles on rough paths, or in a helicopter sling load. Seven chambers were made available at each site under demanding conditions and none of the 35 chambers failed after a series of field metabolic and nutrient uptake measurements. The chambers were hardy enough to withstand shipping, transport, and field conditions without incident. However, chambers still should be moved with care, and we do not advise lifting them when full because of the increase in mechanical stress with greater mass.

Individual chambers are relatively light $(7 \mathrm{~kg})$ and can be easily carried under one arm or stacked and strapped to a frame backpack. All parts needed to run the chambers can fit inside its chamber, and up to 6 chambers can be run for a few hours with 1 portable $12-\mathrm{V}$ battery. Up to 16 sets of samples have been analyzed for CR, gross pri- 


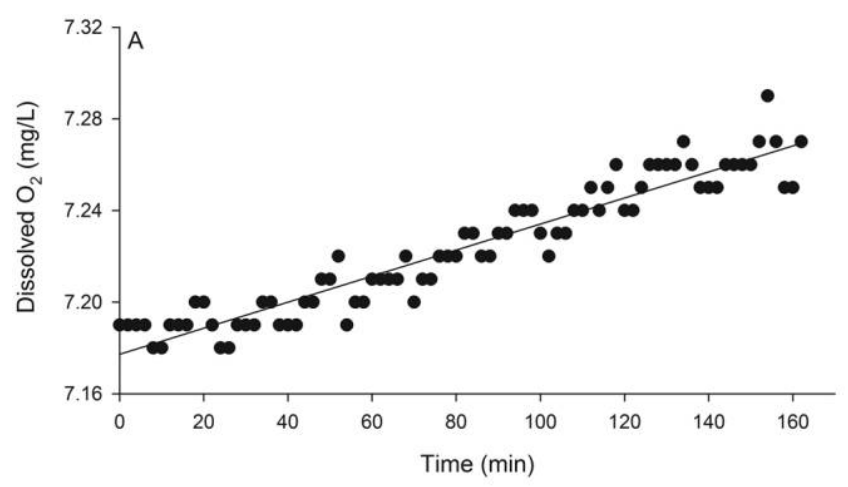

very hot weather $\left(>40^{\circ} \mathrm{C}\right)$, but measurements of metabolism can be shortened during times of rapid linear change in $\mathrm{O}_{2}$ associated with greater metabolic rates in warmer waters. In our representative case, 12 min yielded reliable results, a period in which temperature increased by $<0.2^{\circ} \mathrm{C}$. We advise testing for linearity with natural substrata to estimate the shortest possible period for measurements with each site's substrata. Conditions during short sampling periods will be more likely to resemble in-stream temperatures and background water chemistry, and short incubations will reduce effects of incomplete seal from the atmosphere. The appropriate period is likely to be specific to a site and will depend on biological activity, water-air temperature difference, and $\mathrm{O}_{2}$ saturation. If changes in temperature are of concern, the chambers can be placed in the stream with only the motor above water to reduce heating by surrounding air and to dissipate heat energy into stream water.

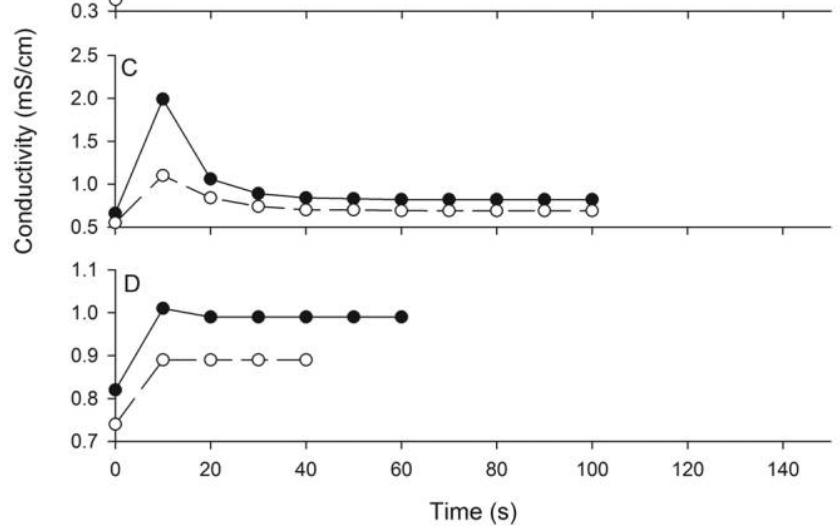

Figure 5. Characteristics of chamber related to diffusion of dissolved $\mathrm{O}_{2}$ (A) and mixing of a concentrated solution of $\mathrm{NaCl}$ (measured as conductivity) with $0.2 \mathrm{~A}$ (B), $0.5 \mathrm{~A}$ (C), and $1.5 \mathrm{~A}$ (D) motor current (velocity) in 2 chambers.

mary production (GPP), and $\mathrm{NH}_{4}{ }^{+}$uptake in the span of a field day using 6 chambers.

\section{DISCUSSION}

We presented a design for an easy-to-build, inexpensive chamber that can replicate field conditions and can be used to measure biogeochemical activity of benthic substrata under unidirectional flow conditions. Investigators rarely publish detailed accounts of chamber performance characteristics or details of tradeoffs that arise with a specific design. Here, we present the strengths and weaknesses we found and try to generalize the process for others who adopt similar designs. Where possible, we also try to indicate tradeoffs and shortcomings of our design to enable other investigators to improve on or alter our design to meet their specific goals.

We wanted realistic flow and temperatures inside the chambers. Flows were similar to those reported with finescale flow measurements in real streams (Dodds 1991). Temperatures did rise during field conditions $\left(\sim 1^{\circ} \mathrm{C} / \mathrm{h}\right)$ in
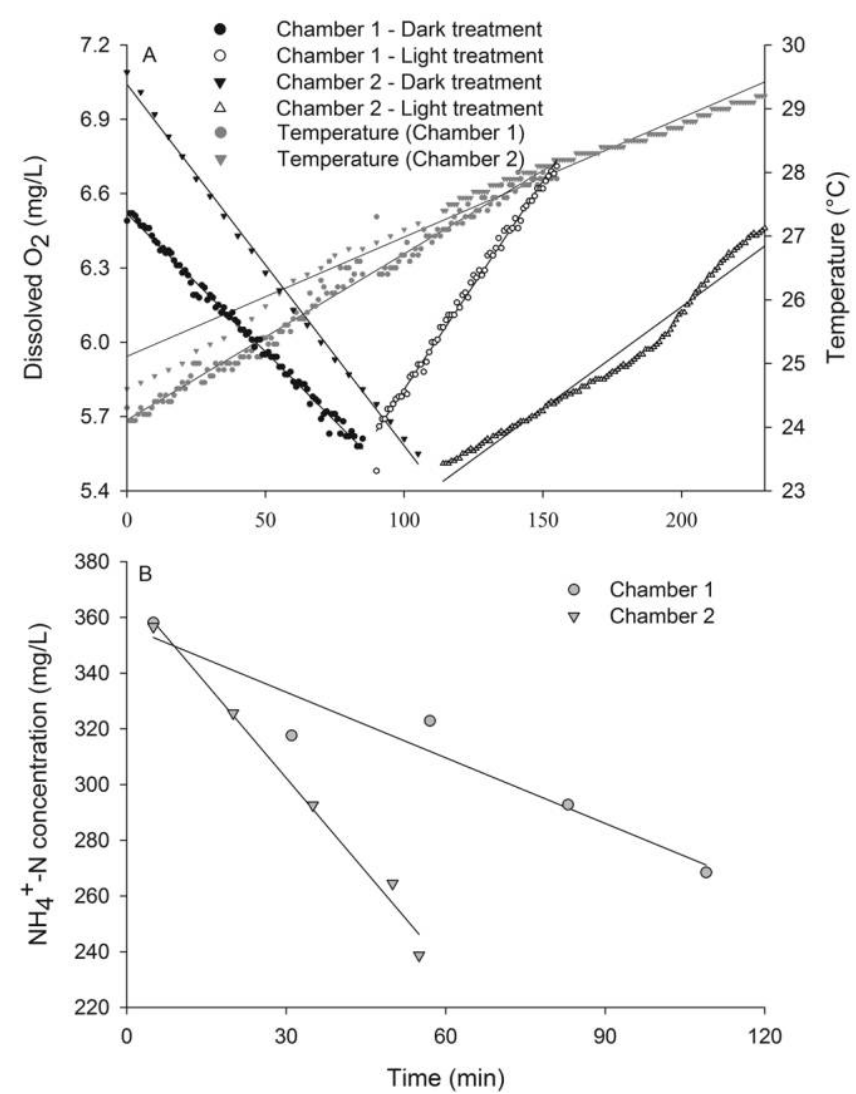

Figure 6. Field measurements of benthic metabolism (A) and nutrient uptake (B) in 2 chambers with sediments that had been incubated in the stream for $30 \mathrm{~d}$ under different in-stream conditions. Dissolved $\mathrm{O}_{2}$ was measured every minute (except for the dark treatment in chamber 2), whereas 5 water samples were collected over time to estimate $\mathrm{NH}_{4}{ }^{+}$. Time intervals were based on changes in $\mathrm{O}_{2}$ (see Methods for details). Dark and light treatments were made with a dark cover over the chamber or ambient light, respectively. 
Table 3. Field measurements of metabolic rates (negative values indicate consumption) made with 2 sets of incubated substrata in 2 different chambers. For original data used in the regressions see Fig. 6.

\begin{tabular}{lcccc}
\hline \multicolumn{1}{c}{ Measured rate } & Chamber & Slope & $r^{2}$ & Rate based on Eq. 1 \\
\hline Community respiration: dark & 1 & $-0.011 \mathrm{mg} \mathrm{O}_{2} \mathrm{~min}^{-1} \mathrm{~L}^{-1}$ & 0.994 & $-0.220 \mathrm{~g} \mathrm{O}_{2} \mathrm{~m}^{-2} \mathrm{~h}^{-1}$ \\
& 2 & $-0.015 \mathrm{mg} \mathrm{O}_{2} \mathrm{~min}^{-1} \mathrm{~L}^{-1}$ & 0.997 & $-0.306 \mathrm{~g} \mathrm{O}_{2} \mathrm{~m}^{-2} \mathrm{~h}^{-1}$ \\
Net community production: light & 1 & $0.017 \mathrm{mg} \mathrm{O}_{2} \mathrm{~min}^{-1} \mathrm{~L}^{-1}$ & 0.992 & $0.340 \mathrm{~g} \mathrm{O}_{2} \mathrm{~m}^{-2} \mathrm{~h}^{-1}$ \\
& 2 & $0.008 \mathrm{mg} \mathrm{O}_{2} \mathrm{~min}^{-1} \mathrm{~L}^{-1}$ & 0.969 & $0.163 \mathrm{~g} \mathrm{O}_{2} \mathrm{~m}^{-2} \mathrm{~h}^{-1}$ \\
$\mathrm{NH}_{4}{ }^{+}$uptake: nutrient pulse addition & 1 & $-0.785 \mu \mathrm{g} \mathrm{NH}_{4}{ }^{+}-\mathrm{N} \mathrm{min}^{-1} \mathrm{~L}^{-1}$ & 0.918 & $-0.016 \mathrm{mg} \mathrm{NH}_{4}{ }^{+}-\mathrm{N} \mathrm{m}^{-2} \mathrm{~h}^{-1}$ \\
& 2 & $-2.246 \mu \mathrm{g} \mathrm{N} \mathrm{H}_{4}{ }^{+}-\mathrm{N} \mathrm{min}^{-1} \mathrm{~L}^{-1}$ & 0.987 & $-0.046 \mathrm{mg} \mathrm{NH}_{4}^{+}-\mathrm{N} \mathrm{m}^{-2} \mathrm{~h}^{-1}$ \\
\hline
\end{tabular}

We required a chamber that enabled us to detect changes in dissolved gases. Diffusion to the atmosphere across the lid was minimal, but in conditions of low biological activity, such diffusion may become important. It might be possible to increase seals by using an additional sealant along the chamber lid, shaft, and probe connections. However, gas exchange/h was close to the detection limit, so a better seal probably would have made little difference for our applications. We suggest using a more-expensive, tighter shaft coupling if more stringent gas-tight measurements are required. We are unaware of diffusion and sealing capacity published for other field-chamber designs, so are unable to compare diffusion rates among designs.

The chambers have some inherent drawbacks that may limit their experimental capabilities. Some of these drawbacks can be remedied by changing the design. Velocities for a specific amperage varied across chambers probably because of variation in the friction of the drive-shaft seal. If a specific velocity is needed, we suggest establishing an amperage-velocity relationship for the specific chamber and shaft placement. Very high water velocities, such as those found in very rapidly flowing streams, were not achieved (maximum $=0.14 \mathrm{~m} / \mathrm{s})$. More powerful motors to drive the propellers could remedy flow limitations, but would consume more power. We did not achieve completely laminar flow, and previously published work (see Vogel 1996) suggests the chamber flow area should be $3 \times$ longer than the working area to achieve laminar flow. However, $30-\mathrm{cm}$ working length for these chambers would translate into a chamber $\geq 1.2 \mathrm{~m}$ long. Our relative dimensions are similar to those used by Dodds and Brock (1998), and like them, we found only moderate turbulence. Flow collimators, such as those used by Dodds and Brock (1998), could increase laminar flow but would increase drag and potentially decrease flow velocities for similar currents provided. We needed portable chambers, so we had to accept a restriction on the size of samples and chambers. The small chamber-volume:sample-surface area ratio allowed us to detect changes in $\mathrm{O}_{2}$ and $\mathrm{NH}_{4}{ }^{+}$concentrations quickly. However, a low ratio could pose a problem if biotic activity is high $\left(\mathrm{O}_{2}\right.$ and nutrients might be consumed too quickly) or incubations had to be maintained for longer periods (difficulty maintaining ambient conditions). Larger dimensions could easily solve this issue, but larger chambers would be less durable and thicker acrylic rapidly increases weight and cost. If more realistic light spectral characteristics are needed, more expensive ultraviolet-lighttransparent plastic is available (see Dodds and Brock 1998). Thus, the chambers can be adapted in several ways to address drawbacks, but most alterations will affect one of the other objectives set for the chamber design presented. Our design is robust, portable, and cheap and provides chamber conditions that are representative of instream flow, light, and temperature conditions.

The chambers also have considerable advantages. Construction is relatively straightforward, and the design is simple and modular. Perhaps the most important recommendation in construction is to cut the plastic as cleanly as possible. Construction time decreases and ease of obtaining water-tight seals increases dramatically when edges of pieces require little smoothing. The modular design helped when cleaning chambers in the field because parts could be rinsed separately in the stream and reassembled easily. Parts can be exchanged among chambers, so if one part breaks, parts can be borrowed from a chamber not in use. All materials were ordered online or bought at a local hardware store, and materials can easily be obtained to fix any broken parts rather than having to replace the entire chamber. The largest expenses were the acrylic plastic pieces ( $\sim$ \$SS250/chamber for plastic and $\sim \$ U S 50$ for specialized cutting) and labor. Building the chambers took $\sim 15$ person-hours depending on other tasks during wait times. Our labor costs were low (skilled undergraduate help, on-campus machine cutting), but using a machinist could make labor the greatest cost. Our costs/chamber (based on bulk purchase of parts to build 35 chambers) were $\$$ US400 for materials and parts (Table 1) and \$US50 for cutting. In addition, salary for $\sim 15 \mathrm{~h}$ of construction labor/chamber was required ( $\sim$ \$S175 in our case) resulting in a total of \$US625 for each chamber.

\section{Comments and recommendations}

The chambers can be modified easily for studies of other stream organisms, substrate types, or processes. We have used the chambers for measuring respiration rates 
of leaves and photosynthesis and respiration of macrophytes by placing materials in mesh bags that were tied to the internal sample table. With modest modification, these chambers could be used to measure metabolic and excretion characteristics of larger animals, such as fish or crayfish. Other benthic N-cycling rates, such as denitrification and nitrification, have been measured simultaneously in similar chambers with acetylene addition (Teissier and Torre 2002) and could easily be measured in chambers with our design. Moreover, such chambers could be used for solutes other than nutrients, such as radioisotope or toxins, because the chambers are easy to disassemble and clean. The use of chambers for toxicity tests may be complicated by our use of materials, such as the brass from shafts, which have known toxic effects, but brass could be replaced with nontoxic materials such as stainless steel. Overall, we see potential for a wide variety of uses by aquatic ecologists interested in measurements made at small spatial scales in systems with unidirectional flow.

\section{ACKNOWLEDGEMENTS}

We thank Josiah Maine for initial design input and prototype construction, Ty Schaef, Jason Fisher, and Taylor Laskowski for help with assembly, and the SCALER research group for field assessment. We are grateful for the anonymous referees who improved this manuscript through their careful suggestions. We thank Brad Cardinale for the use of the Vectrino ADV. This research was funded by US National Science Foundation Macrosystems grant EF1065255. This is publication no. 442 from the Kansas Agricultural Experiment Station.

\section{LITERATURE CITED}

Alexander, R. B., R. A. Smith, and G. E. Schwarz. 2000. Effect of stream channel size on the delivery of nitrogen to the Gulf of Mexico. Nature 403:758-761.

Beaulieu, J. J., J. L. Tank, S. K. Hamilton, W. M. Wollheim, R. O. Hall, P. J. Mulholland, B. J. Peterson, L. R. Ashkenas, L. W. Cooper, and C. N. Dahm. 2011. Nitrous oxide emission from denitrification in stream and river networks. Proceedings of the National Academy of Sciences of the United States of America 108:214-219.

Berninger, U.-G., and M. Huettel. 1997. Impact of flow on oxygen dynamics in photosynthetically active sediments. Aquatic Microbial Ecology 12:291-302.

Bott, T. L., J. T. Brock, A. Baattrup-Pedersen, P. A. Chambers, W. K. Dodds, K. T. Himbeault, J. R. Lawrence, D. Planas, E.
Snyder, and G. M. Wolfaardt. 1997. An evaluation of techniques for measuring periphyton metabolism in chambers. Canadian Journal of Fisheries and Aquatic Sciences 54:715725.

DeNicola, D. M. 1996. Periphyton responses to temperature at different ecological levels. Pages 150-182 in R. J. Stevenson, M. L. Bothwell, and R. L. Lowe (editors). Algal ecology: freshwater benthic ecosystems. Academic Press, San Diego, California.

Dodds, W. K. 1991. Micro-environmental characteristics of filamentous algal communities in flowing freshwaters. Freshwater Biology 25:199-209.

Dodds, W. K., B. J. F. Biggs, and R. L. Lowe. 1999. Photosynthesisirradiance patterns in benthic microalgae: variations as a function of assemblage thickness and community structure. Journal of Phycology 35:42-53.

Dodds, W. K., and J. Brock. 1998. A portable flow chamber for in situ determination of benthic metabolism. Freshwater Biology 39:49-59.

Dodds, W. K., A. M. Veach, C. M. Ruffing, D. M. Larson, J. L. Fischer, and K. H. Costigan. 2013. Abiotic controls and temporal variability of river metabolism: multiyear analyses of Mississippi and Chattahoochee River data. Freshwater Science 32:1073-1087.

LaBarbera, M., and S. Vogel. 1976. An inexpensive thermistor flow meter for aquatic biology. Limnology and Oceanography 21:750-756.

O'Brien, J. M., and W. K. Dodds. 2008. Ammonium uptake and mineralization in prairie streams: chamber incubation and short-term nutrient addition experiments. Freshwater Biology 53:102-112

Mulholland, P. J., A. M. Helton, G. C. Poole, R. O. Hall, S. K. Hamilton, B. J. Peterson, J. L. Tank, L. R. Ashkenas, L. W. Cooper, C. N. Dahm, W. K. Dodds, S. E. G. Findlay, S. V. Gregory, N. B. Grimm, S. L. Johnson, W. H. McDowell, J. L. Meyer, H. M. Valett, J. R. Webster, C. P. Arango, J. J. Beaulieu, M. J. Bernot, A. J. Burgin, C. L. Crenshaw, L. T. Johnson, B. R. Niederlehner, J. M. O’Brien, J. D. Potter, R. W. Sheibley, D. J. Sobota, and S. M. Thomas. 2008. Stream denitrification across biomes and its response to anthropogenic nitrate loading. Nature 452:202-205.

Solorzano, L. 1969. Determination of ammonia in natural waters by the phenolhypochlorite method. Limnology and Oceanography 14:799-801.

Teissier, S., and M. Torre. 2002. Simultaneous assessment of nitrification and denitrification on freshwater epilithic biofilms by acetylene block method. Water Research 36:3803-3811.

Vogel, S. 1996. Life in moving fluids: the physical biology of flow. Princeton University Press, Princeton, New Jersey. 